\title{
MANAJEMEN EKONOMI KELUARGA DALAM PERSPEKTIF BUDDHIS
}

\author{
Mulyana \\ STAB Negeri Sriwijaya \\ mulyanawahyu45@gmail.com
}

\begin{abstract}
This study aims to describe how the economic management of the family in the Buddhist perspective. This study uses literature review. Data used in the form of opinions, ideas, or the ideas about management, economics, family, and the values of Buddhism related to economic compiled from various sources of relevant literature. Data were analyzed with content analysis. The results shows that the management as a modern concept can be combined with the values contained in the teachings of Buddhism in an effort to manage the family's economy. Management concepts can be used to manage the family's economy, so that all available resources can be used effectively and efficiently. While the values of Buddhism provides guidance on how a family can meet the needs of the material in ways to earn without neglecting morality, wealth that has been obtained is save or guarded, and its use, as well as the mental attitude in looking at wealth owned. The final results from the combination of management and the values of Buddhism is the creation of prosperity for the family inwardly and outwardly, community, and environment.
\end{abstract}

Keywords: economic, management, Buddhism

\section{Pendahuluan}

Dalam kehidupan sehari-hari, setiap orang selalu melakukan aktivitas yang berkaitan dengan ekonomi. Kegiatan ekonomi dilakukan untuk memenuhi kebutuhan manusia yang beraneka ragam, seperti kebutuhan pangan, sandang, dan papan. Selain itu, kebutuhan seperti kesehatan, pendidikan, sarana transportasi, hiburan, dan sarana telekomunikasi juga tidak kalah pentingnya. Untuk memenuhi berbagai macam kebutuhan tersebut manusia harus mencari nafkah atau bekerja. Seseorang harus memilih pekerjaan yang sesuai dengan kemampuan yang dimiliki.

Dalam kehidupannya, manusia selalu berhubungan dengan aturan-aturan atau norma seperti ajaran agama yang dianut. Ajaran agama tersebut berfungsi sebagai pedoman atau pengendali berbagai aktivitas manusia yang meyakininya. Nilai-nilai yang terkandung dalam ajaran agama dimplementasikan dalam keseharian sebagai pedoman untuk menjalani kehidupan. Agama juga memberikan pedoman bagaimana seseorang harus bekerja mencari nafkah dan bagaimana menggunakan penghasilan tersebut untuk menyokong kehidupannya. Banyak penelitian yang menunjukkan bahwa nilai-nilai keagamaan seseorang dapat berkontribusi positif, seperti kemampuan untuk mengurangi stres pada saat bekerja, mempengaruhi sikap etis individu, dan motivasi dalam bekerja.

Idealnya, kekayaan yang diperoleh dari bekerja seharusnya dimanfaatkan untuk memenuhi kebutuhan dan sebagian disimpan untuk investasi, pengembangan usaha, dan cadangan yang dapat digunakan pada saat mengalami kesulitan. Saat ini, pemahaman tentang ekonomi didominasi oleh konsep dari dunia Barat yang bersifat liberal dan materialistik. Pengaruh dominan dari konsep ekonomi liberal dan materialistik telah meresap ke setiap lapisan dari lingkup yang sempit seperti individu 
dan keluarga sampai lingkup yang luas seperti negara. Pengaruh tersebut telah membentuk cara pandang manusia sehingga menjadi lebih materialistik dan konsumtif.

Pada kenyataannya, untuk memperoleh pekerjaan yang sesuai dengan keinginan dan kemampuan tidak selalu mudah, terlebih lagi jika harus memperhatikan nilai-nilai agama yang dianut. Saat ini, masih banyak orang yang beranggapan bahwa pekerjaan dan nilai-nilai spiritual keagamaan merupakan dua hal yang terpisah. Orang yang setiap hari rajin beribadah tetapi dalam bekerja masih menggunakan cara-cara yang tidak layak. Kasus korupsi yang terjadi di lingkungan kementerian agama merupakan salah satu contohnya.

Kekayaan yang dimiliki keluarga harus dimanfaatkan secara optimal. Untuk memberikan manfaat yang optimal, dibutuhkan pengelolaan atau manajemen berkaitan dengan ekonomi rumah tangga secara efektif dan efisien, sehingga memberikan manfaat yang seimbang bagi diri sendiri, orang lain, maupun lingkungan. Konsep manajemen modern dan nilai-nilai spiritual dapat dikolaborasikan dalam pengelolaan ekonomi keluarga sehingga manfaat optimal dari kekayaan yang dimiliki keluarga dapat tercapai. Kolaborasi antara manajemen dan ekonomi Buddhis dapat menjadi solusi yang tepat dalam mewujudkan keluarga hita sukhaya dalam upaya mencapai kebahagiaan dan tujuan akhir umat Buddha, yaitu nibbâna.

\section{Metodologi Penelitian}

Penelitian ini menggunakan metode kajian pustaka. Data yang digunakan berupa pendapat, gagasan, atau hasil pemikiran mengenai manajemen, ekonomi, keluarga, dan nilai-nilai ajaran Buddhisme yang berkaitan dengan ekonomi yang dikumpulkan dari berbagai sumber pustaka yang relevan. Data yang diperoleh dianalisis dengan metode content analysis, dimana data yang berupa pendapat, gagasan, maupun hasil pemikiran dianalisis untuk mendapatkan suatu kesimpulan secara deduktif-induktif.

\section{Pembahasan}

\section{Konsep Manajemen Ekonomi Keluarga}

Terbentuknya bahtera kehidupan rumah tangga idealnya didahului dengan suatu planning atau rencana, dari rencana yang ada direalisasikan dalam kegiatan untuk mencapai tujuan dari kehidupan berumah tangga (Jhana Virya, 2009: 5). Pengelolaan ekonomi keluarga merupakan faktor penting dalam menentukan kesejahteraan hidup anggota keluarganya meskipun kesejahteraan tidak hanya ditentukan oleh perekonomian semata. Pengelolaan ekonomi di era globalisasi sangatlah penting, seperti yang dinyatakan oleh Dhammananda bahwa the present world is a materialistic world and in order to meet your material needs, proper financing and budgeting is essential (http://www.accesstoin-sight.org/lib/authors/-dhamma-nanda/marriage.-html).

Manajemen ekonomi merupakan cara-cara atau strategi yang harus dipertimbangkan untuk mengelola perekonomian untuk mencapai kesejahteraan hidup. Economic management is considered as an important strategy for ensuring a good standard of living for all beings in the present world scenario (Arvind K. Singh, 2012: 74). Pengelolaan ekonomi rumah tangga bertujuan untuk mendayagunakan kesadaran, sikap, perilaku, dan kemampuan anggota keluarga serta menggerakkan potensi ekonomi keluarga guna memastikan adanya: (1) pemenuhan kebutuhan ekonomi anggota keluarga secara optimum; (2) stabilitas kehidupan ekonomi keluarga; dan (3) pertumbuhan ekonomi keluarga (Danny Sutjiono, 2005: 4). Dengan penerapan manajemen ekonomi keluarga 
diharapkan kebutuhan ekonomi keluarga dapat terpenuhi, stabilitas perekonomian keluarga tercapai, dan kesejahteraan keluarga semakin meningkat.

Cara-cara atau strategi penting sangat berguna dalam rangka pengelolaan seluruh sumber daya yang dimiliki untuk memenuhi kebutuhan seluruh anggota keluarga. Pengelolaan dimulai dari merencanakan sumber penghasilan, strategi untuk mencapai, menentukan sumber daya yang dibutuhkan, dan indikator pencapaian. Pengorganisasian dilakukan dengan mengalokasikan sumber daya yang dimiliki, membagi tugas, dan tanggung jawab masing-masing anggota keluarga. Pelaksanaan berhubungan dengan aktualisasi semua tujuan yang sudah direncanakan dan diorganisasikan. Pengawasan digunakan untuk mengawasi penggunaan sumber daya yang ada sehingga tepat sasaran, efektif, dan efisien.

\section{Ekonomi Buddhis}

Banyak orang yang beranggapan bahwa agama Buddha merupakan agama pertapaan yang tidak tertarik pada urusan duniawi. Anggapan tersebut tentu saja tidak tepat. Bagaimanapun juga, agama Buddha selalu bersentuhan dengan kehidupan duniawi. Laszlo Zsolnai (2011: 3), menyatakan bahwa "Buddhisme has a well-developed social facet and Buddhist are often engaged in progressive social change". Kontribusi Buddhisme dalam kehidupan sosial salah stunya adalah di bidang ekonomi. Buddhisme berusaha memberikan sumbangan nilai-nilai atau pemikiran dalam mengupayakan perkembangan ekonomi menuju ke arah yang lebih baik. Para pemikir Buddhis menyebut ekonomi yang menggunakan prinsip atau nilai-nilai dari ajaran Buddha dengan Ekonomi Buddhis atau Buddhist Economic. Buddhist economics incorporates the values of middle path, compassion, and balanced life into the pursuit of economic activity (Chandima Wijebandara, 2012: 26). The main purpose of Buddhist Economics is to reduce pain or suffering for all living being (Laszlo Zsolnai, 2011: 11). Arvind K. Singh (2012: 74) mengemukakan bahwa Buddhist economics is a model that supports the conventional forces and a free market and competition without destroying either nature or human society. Karunatilake (1976) dalam Peter Harvey (2000: 16) memaknai ekonomi Buddhis sebagai an economic system suitable to the modern world based on the discourses made by the Buddha. Schumacher (1975) dalam Peter Harvey (2010: 219) menyatakan bahwa Buddhist economics must be very different from the economics of modern materialism, since the Buddhist sees the essence of civilization not in a multiplication of human wants but in the purification of human character formed primarily by a man's work. Prem R. Uprety (1996: 120) menuliskan an alternative model for development in the light of Buddhist teaching and practices and can be safely labeled as "The Economics of Buddhism" as opposed to conventional economics founded by Adam Smith and further developed by his jealous cucessors like Jeremy Bentham. Ekonomi Buddhis sebagai aplikasi dari ajaran Buddha untuk meningkatkan pemahaman tentang moral dan nilai-nilai yang hilang dalam ekonomi neo-klasik model Barat. Pendekatan ekonomi Buddhis menyediakan pemahaman yang lebih berkaitan dengan sumber daya sosial untuk meningkatkan kesejahteraan masyarakat (Wanna Prayukvong, 2007: 162). Kunci dari ekonomi Buddhis adalah kesederhanaan, ekologi, dan tanpa kekerasan (Lloyd Field, 2009: 141).

Ekonomi Buddhis mulai populer sejak kedatangan E. F. Schumacher ke Burma pada tahun 1950-an. Schumacher menemukan bahwa masyarakat Burma dan yang lainnya mengadopsi secara membuta rencana pembangunan yang berasal dari Barat, tanpa mempertimbangkan pandangan hidup umat Buddha yang disebut ekonomi Buddhis (Peter Harvey, 2000: 216). Schumacher menemukan adanya benturan yang disebabkan oleh perbedaan antara ekonomi modern dan ekonomi Buddhis dalam 
penggunaan sumber daya alam (Woo, 2009: 12). Schumacher berargumen bahwa jalan yang tepat dalam pembangunan adalah Jalan Tengah, yaitu antara materialistis yang berlebihan dan cara tradisional yang sangat lamban (Peter Harvey, 2000: 216).

Payutto (1999) menawarkan gagasan ekonomi dalam perspektif Buddhis. Payutto (2005: 30-55) menjelaskan sebelas pandangan Buddhis berkenaan dengan konsep ekonomi modern, yaitu: nilai (value), konsumsi (consumption), kesederhanaan/sikap tidak berlebihan (moderation), pembatasan konsumsi (nonconsumption), konsumsi berlebihan (overconsumption), rasa puas, kerja (work), produksi dan bukan produksi (production and non-production), persaingan dan kerja sama (competition and cooperation), pilihan (choice), dan pandangan hidup (life views). Payutto dalam Laszlo Zsolnai (2011: 6-7) merangkum karakteristik penting dari ekonomi Buddhis, sebagai berikut: realization of true well-being dan not harming one self or other.

Shinichi Inoue (1997: 67-72) mengemukakan tiga esensi dari ekonomi Buddhis, yaitu: (1) an economics that benefits oneself and others; (2) an economics of tolerance and peace; dan (3) an economics that can save the earth. Dengan alasan ini, Tanaka Mitsuru dalam Shinichi Inoue (1997: 97-100) menyusun tabel yang disebut dengan the environmental and social assessment categories of production and consumption.

Tabel 1. The Environmental and Social Assessment Categories of Production and Consumption

\begin{tabular}{|c|c|c|c|c|}
\hline & $\mathrm{P}_{1}$ & $\mathrm{P}_{2}$ & $\mathrm{P}_{3}$ & $\mathrm{P}_{4}$ \\
\hline $\mathrm{C}_{1}$ & 1 & 2 & 3 & 4 \\
\hline $\mathrm{C}_{2}$ & 2 & 4 & 6 & 8 \\
\hline $\mathrm{C}_{3}$ & 3 & 6 & 9 & 12 \\
\hline $\mathrm{C}_{4}$ & 4 & 8 & 12 & 16 \\
\hline
\end{tabular}

Untuk nilai kombinasi antara (P) dan (C) semakin kecil angka dari hasil kombinasi produksi dan konsumsi maka semakin baik untuk lingkungan dan masyarakat, karena tidak memberikan dampak negatif. Kombinasi dengan nilai terbesar adalah paling buruk, yaitu merusak lingkungan dan tidak menguntungkan masyarakat.

Pada tahun 1997, Raja Thailand mengemukakan model ekonomi baru yang dikenal dengan "The Royal Thai Sufficiency Economy Model" dalam menghadapi krisis ekonomi yang terjadi pada saat itu (Essen, 201l: 65). Raja lebih menekankan untuk dukungan ekonomi lokal (self-supporting economy). Pada tahun yang sama, di Thailand juga muncul gerakan yang menyebut dirinya sebagai gerakan Santi Asoke (Santi Asoke Buddhist Reform Movement of Thailand) yang mengkritisi kapitalisme, khususnya masalah keserakahan (greed), persaingan (competition), dan eksploitasi (exploitation) sebagai penyebab permasalahan masyarakat. The Royal Thai Sufficiency Economy Model dan Santi Asoke Buddhist Reform Movement of Thailand mengusung misi yang kurang lebih sama. Less directly, they are both conducive to economic activity that is more socially just and environmentaly sustainable due to their ethics of self-reliance, moderation, and interdependency (Essen, 2011: 61-62).

Seorang ahli ekonomi Thailand, Apichai Puntasen (2005) dalam Laszlo Zsolnai (2011: 10) menyarankan bahwa cara-cara yang digunakan dalam memproduksi suatu barang menurut ekonomi Buddhis dapat didefinisikan sebagai pañnaism. Humman beings who have panna do not seek to maximize pleasure or quality but seek to be relived of and relieve others 
of pain as much as possible (Laszlo Zsolnai, 2011: 10). Richard Welford menyatakan bahwa Buddhisme dapat menjadi sumber kepuasan hati yang lebih besar dan lebih konsisten dalam pemeliharaan alam dan menjaga lingkungan (Laszlo Zsolnai, 2011: 9). Serge Christopher Kolm, seorang ekonom Prancis (1985) membangun sebuah model formal yang menggabungkan konsumsi dan meditasi secara bersamaan dalam usaha untuk memperoleh kebahagiaan. The Buddha says that the optimum is some meditation to lower the desire of consumption and thus to work that it entails, this is the "Middle Way" (Laszlo Zsolnai, 2011: 5). Pandangan dan gagasan yang dikemukakan oleh pemikir Buddhis tersebut jika dirunut akan mengerucut pada Jalan Tengah Berunsur Delapan (ariya atthangika magga), yang scara spesifik mengacu pada penghidupan benar (samma ajiva). Meskipun demikian, kedelapan unsur harus dijalankan secara bersamaan dan seimbang.

Penghidupan benar (samma ajiva), ucapan benar (samma vaca), dan perbuatan benar (samma kammanta) dikelompokkan dalam satu aturan disiplin moralitas (sîla) yang merupakan bagian dari Jalan Mulia Berunsur Delapan (ariya atthangika magga). Sebagai aturan disiplin, penghidupan, ucapan, dan perbuatan benar harus dilaksanakan secara bersamaan. Right livelihood is a practice of earning a living in righteous way, by not violating, right speech, and right action (Piboolsravut, 1997: 30). Ucapan dan perbuatan benar merupakan syarat yang harus diterapkan dalam bekerja atau mencari nafkah sehingga seseorang dapat berpenghidupan benar. Sîla sebagai aturan disiplin moral tidak hanya sebagai panduan dalam melakukan tindakan, tetapi yang lebih penting adalah sebagai sarana untuk membantu memurnikan batin. Aturan disiplin moral menjadi landasan penting dalam upaya mencapai tujuan tertinggi, nibbâna.

Penghidupan benar merupakan aturan moral yang bertujuan untuk memastikan bahwa seseorang bekerja untuk memperoleh penghasilan dengan cara yang benar. Right livelihood is the basis of Buddhist economic and deals directly with the issue of economic wellbeing (Piboolsravut, 1997: 31). Right livelihood involves finding a way to make a living that benefits both ourself and others (Fine, 2008: 67). Secara spesifik, kesejahteraan material berkaitan dengan kekayaan atau keuangan. Kekayaan harus diusahakan, setelah mendapatkan harus dikelola dalam pemanfaatannya, dan sikap mental dalam memandang kekayaan tersebut, yang semuanya harus direncanakan dengan baik. Menurut Buddhisme maupun berdasarkan analisis modern, perencanaan keuangan (kekayaan) dapat dikelompokkan ke dalam tiga bagian, yaitu: bagaimana memperoleh penghasilan dan menggunakannya untuk memenuhi kebutuhan, investasi, dan sebagai simpanan untuk keadaan darurat dan masa pensiun (Kekanadure Dhammasiri, 2010: 16). Memperhatikan peran kekayaan material, Cornelis Wowor (2004: 25), menyimpulkan empat prinsip pokok yang harus diperhatikan, yaitu: (l) sebagai sarana untuk memenuhi kebutuhan fisik dasar, dianjurkan untuk mengumpulkan kekayaan materi; (2) di dalam usaha untuk memperoleh hendaknya ditempuh dengan cara-cara yang tidak melanggar hukum dan tidak menggunakan kekerasan; (3) pemanfaatan kekayaan hendaknya menghasilkan kesejahteraan dan suka cita bagi diri sendiri dan orang lain, "demi kebahagiaan masyarakat", termasuk penyantunan lembaga-lembaga keagamaan; dan (4) dari sudut penilaian lebih dalam, hendaknya pemilikan kesejahteraan material itu tidak membuat ketika menjadi budak dan kenikmatan indera demikian rupa sehingga kita meremehkan pembinaan rohani dan mengabaikan usaha mencapai nilainilai rohani. Berkaitan dengan penghasilan, Lloyd Field (2009: 186) menganjurkan bahwa seseorang harus waspada terhadap keinginan dan sebab akibat yang terlibat di dalamnya.

Penghidupan benar merupakan dasar dari ekonomi Buddhis dan bersentuhan secara langsung dengan kesejahteraan ekonomi (Piboolsravut, 1997: 31). Umat Buddha 
berusaha mencari kekayaan harus menggunakan aturan-aturan tertentu sebagai pedoman. One should acquire it only by legal means, not illegally; one should acquire it peacefully, without coercion or violence; one should acquire it honestly, not by trickery or deceit; and one should acquire it in ways which do not entail harm and suffering for others (http://www.accesstoinsight. org/lib/authors/bodhi/-waytoend.-html\#ch4).

Bodhi menjelaskan bahwa untuk berpenghidupan benar harus memenuhi tiga syarat kebenaran, yaitu kebenaran berkenaan dengan tindakan/perbuatan (rightness regarding actions), kebenaran berkenaan dengan orang yang melakukan tindakan (Rightness regarding persons), dan kebenaran berkenaan dengan objek (Rightness regarding objects). Kebenaran berkenaan dengan tindakan, seseorang harus mengerjakan tugas dengan tekun dan sungguh-sungguh, tidak bermalas-malasan, tidak meninggalkan pekerjaan sebelum waktu bekerja selesai, tidak melaporkan bahwa ia telah bekerja melebihi daripada yang telah dikerjakan, dan tidak membawa pulang barang-barang milik perusahaan. Kebenaran berkenaan dengan orang mengandung makna bahwa pemberi kerja dan karyawan, sesama rekan kerja, dan kepada pelanggan harus saling menghormati sehingga tecipta hubungan yang baik. Pemberi kerja harus memberikan gaji yang layak sesuai dengan pekerjaannya, memberikan pekerjaan yang sesuai dengan kemampuan dan keterampilan yang dimiliki karyawan, memberikan jaminan jenjang karir, memberikan waktu istirahat yang cukup termasuk hari libur, dan memberikan bonus berkaitan dengan prestasi kerja para karyawannya. Sebaliknya, karyawan menghormati dan mengikuti petunjuk yang diberikan atasannya sehingga hubungan atasan dan karyawan tetap terjaga dengan baik. Berkaitan dengan kebenaran berkenaan dengan objek, barang yang diperjualbelikan haruslah barang yang baik, informasi yang disampaikan dalam iklan sesuai dengan spesifikasinya, dan tidak menggunakan cara-cara yang tidak baik dalam melakukan transaksi bisnis (http://www.accesstoinsight.org/lib/authors/bodhi/-waytoend-html \#ch4).

\section{Manajemen Ekonomi Keluarga dalam Perspektif Buddhis}

Manajemen ekonomi keluarga merupakan upaya untuk mendayagunakan kesadaran, sikap, perilaku, dan kemampuan seluruh anggota keluarga serta menggerakkan potensi ekonomi keluarga yang bertujuan untuk memenuhi kebutuhan anggota keluarga secara optimum, menjaga keseimbangan perekonomian, dan meningkatkan pertumbuhan ekonomi keluarga. Kesadaran, sikap, perilaku, dan kemampuan yang dikembangkan didasarkan pada nilai-nilai yang terkandung dalam ajaran agama Buddha dalam memperoleh dan menggunakan pendapatan serta sikapnya terhadap kekayaan yang dimiliki. The present world is a materialistic world and in order to meet your material needs, proper financing and budgeting is essential (http://www. accesstoinsight.org/lib/-authors/ dhammananda/marriage.html). Menurut Buddhisme maupun berdasarkan analisis modern, perencanaan keuangan dapat dikelompokkan ke dalam tiga bagian, yaitu: bagaimana memperoleh penghasilan dan menggunakannya untuk memenuhi kebutuhan, investasi, dan sebagai simpanan untuk keadaan darurat dan masa pensiun (Kekanadure Dhammasiri, 2010: 16). Piboolsravut (1997: 149) menyebutkan tiga jenis aktivitas dalam ekonomi Buddhis, yaitu bagaimana seseorang berusaha untuk memperoleh penghasilan (bekerja), bagaimana kekayaan yang diperoleh dari bekerja harus dijaga, dan bagaimana cara menggunakan kekayaan yang dimiliki dengan benar. 
Kepada pemuda Sigala, Buddha menjelaskan bahwa mengumpulkan kekayaan haruslah seperti lebah yang mengumpulkan madu dan mengumpulkannya seperti gundukan yang dibuat semut. Dalam memperoleh kekayaan harus dilakukan dengan cara yang benar dan tidak dihambur-hamburkan dalam pemanfaatannya. Ketika kekayaan sudah terkumpul, maka perumah tangga harus membaginya ke dalam empat bagian, yaitu seperempat bagian untuk dinikmati (memenuhi kebutuhan sehari-hari), setengahnya untuk diinvestasikan kembali untuk meningkatkan penghasilan di masa depan, dan seperempat bagian lagi ditabung untuk menghadapi masa sulit dan dapat pula digunakan ketika sudah tidak bekerja lagi (Rhys Davids, 2002: 180). Herman S. Endro (1997: 65-66) mengemukakan empat area tentang kekayaan yang harus diperhatikan oleh umat Buddha, yaitu cara memperoleh, penyimpanan, penggunaan, dan sikap mental terhadap kekayaan.

1. Memperoleh Penghasilan

Untuk memenuhi kebutuhannya, manusia harus bekerja agar mendapatkan penghasilan. Kemampuan seseorang dalam memilih pekerjaan sangat bergantung pada faktor internal dan faktor eksternal. Faktor internal merupakan faktor yang berasal dari dalam diri orang tersebut, seperti kesejahteraan, keterampilan, pengetahuan, kecerdasan, sikap, dan intuisi. Faktor eksternal berasal dari lingkungan di luar individu, seperti persaingan kerja, lapangan kerja, budaya masyarakat, kebijakan politik pemerintah, teknologi, sumber daya manusia, sumber daya alam, iklim, demografi, dan kondisi geografis. Kedua faktor tersebut merupakan faktor masukan (input). Factor input of acquiring wealth can be grouped into three categories: (1) external factor input; (2) personal or internal factor input; and (3) the present effort within process (Piboolsravut, 1997: 151). Kombinasi antara faktor internal dan faktor usaha sangat menentukan keberhasilan seseorang. Sjafri Mangkuprawira (2011: 245) mengelompokkan orang dalam empat golongan, yaitu (1) orang yang mampu tetapi tidak mau; (2) orang yang mau tetapi tidak mampu; (3) orang yang mampu sekaligus mampu; dan (4) orang yang tidak mampu dan tidak mau. Untuk mencapai keberhasilan di bidang ekonomi, seseorang harus menjadi tipe ketiga, yaitu mampu dan mau. Tanpa dibarengi dengan usaha yang tekun, kemampuan tidak akan membuat seseorang berhasil.

Merupakan kewajiban umat Buddha untuk mencari dan memiliki kekayaan untuk penghidupannya, dengan syarat kekayaan itu diperoleh dari usahanya sendiri dan sesuai dengan dhamma (Dharma K. Widya, 2004: 31). Dalam Adiya Sutta (keuntungan yang diperoleh dari kekayaan), Buddha menjelaskan kepada seorang perumah tanggan bernama Anathapindika bahwa kekayaan harus diperoleh dengan usahanya, mengumpulkan melalui kekuatan lengannya, dan harus dikumpulkan melalui keringat alisnya sendiri, dan dari usaha tersebut kekayaan pantas diperoleh (Woodward, 2008: 37-38). Buddhism offers a view guides on how to earns' wealth in a moral way (Buddharakkhita, 2011: 33). Buddharakkhita (2011: 33) memberikan contoh bagaimana seseorang dapat memperoleh penghasilan seperti seekor lebah yang mengambil nektar dari sekuntum bunga. Lebah mengambil nektar tanpa merugikan merugikan bunga, justru memberikan keuntungan dengan membantu penyerbukan. Dengan demikian, bunga dan lebah menghasilkan kerja sama yang saling menguntungkan (mutual benefit). Umat Buddha dapat mencontoh lebah dalam memperoleh penghasilan, tanpa merugikan justru memberikan keuntungan kepada orang lain, masyarakat, dan lingkungan.

Kekanandure Dhammasiri (2010: 21) menyatakan bahwa salah satu prinsip terpenting dalam memperoleh pekerjaan menurut Buddhisme adalah bahwa pekerjaan tersebut haruslah legal atau sah dan diakui menurut aturan yang berlaku di negara 
tempat orang tersebut tinggal dan bekerja sesuai dengan waktu dan energi yang digunakan untuk bekerja. Sebagai umat Buddha yang melaksanakan pañcasîla Buddhis, maka dalam bekerja harus memedomani nilai-nilai yang terkandung dalam sîla-sîla tersebut. Seseorang seharusnya memperoleh pencaharian hanya dengan cara yang sah bukan dengan cara gelap, kita seharusnya memperoleh pencaharian dengan cara damai, tanpa pemaksaan ataupun kekerasan; kita seharusnya memperoleh pencaharian secara jujur, bukan dengan tipu daya ataupun muslihat; dan seharusnya memperoleh pencaharian dengan cara yang tidak mendatangkan kerugian maupun penderitaan bagi makhluk lain (Bodhi, 2006: 87). Dalam Sigalovada Sutta, Buddha menjelaskan empat hal yang harus dihindarkan dalam kehidupan sehari-hari. The destruction of life, the taking what is not given, licentiousness, and lying speech (Rhys Davids, 2002: 174).

2. Menggunakan kekayaan

Penggunaan kekayaan harus diawali dengan perencanaan yang matang. Selain itu, penggunaan harta kekayaan haruslah konsisten dengan prinsip-prinsip dalam Buddhisme. Setelah seseorang memperoleh kekayaan, maka ia dapat menggunakan untuk memenuhi kebutuhan sehari-hari. Untuk mempermudah pengelolaan ekonomi (keuangan), Buddha memberi petunjuk kepada pemuda Sigala (Sigalovada Sutta) untuk membagi penghasilannya dalam empat bagian, yaitu seperempat bagian digunakan untuk memenuhi kebutuhan sehari-hari, setengah bagian untuk investasi, dan seperempat bagian untuk tabungan. Petunjuk tersebut memudahkan pengalokasian keuangan. Dengan seperempat bagian dari penghasilan yang diperoleh, sebuah keluarga harus memilah kebutuhan dalam berbagai prioritas, yaitu primer, sekunder, dan tersier.

Dalam Adiya Sutta, Buddha menguraikan lima cara menggunakan kekayaan yang diperoleh agar memberikan keuntungan yang besar, agar memberikan manfaat, kekayaan yang diperoleh harus digunakan dengan benar. Pertama, untuk digunakan sendiri agar hidupnya lebih nyaman, dapat melanjutkan kehidupannya, dan harus digunakan dengan cara yang benar. Selain itu, kekayaan yang dimiliki dapat digunakan untuk menghidupi orangtua, istri dan anak-anaknya, menggaji pembantu, dan pegawai sehingga mereka dapat menjalani hidup dengan layak. Kedua, untuk membantu temantemannya ketika mengalami kesulitan sehingga mereka tetap dapat menjalani kehidupan dengan layak. Ketiga, untuk menjaga keamanan diri sendiri, seperti membayar denda kepada pemerintah ketika melakukan kesalahan, menjaga keamanan dari pencurian, kebakaran, dan banjir, serta untuk melindungi dari teman-teman yang berbuat jahat. Keempat, untuk membuat lima persembahan (dâna), yaitu membantu sanak saudara yang mengalami kesulitan, melayani para tamu, memberikan persembahan atas nama leluhur, membayar pajak kepada pemerintah, dan mendukung perkembangan agama. Kelima, untuk memberikan manfaat yang paling tinggi, kekayaan harus digunakan untuk melayani makhluk suci (menyokong perkembangan agama) yang telah menjauhkan diri dari racun dan kebodohan, sabar dan rendah hati, dan merealisasi nibbâna yang merupakan ladang subur untuk menanam jasa kebajikan yang tiada bandingnya (Woodward, 2008: 37-38).

3. Menyimpan/Menjaga Kekayaan

Kekayaan yang diperoleh dengan kerja keras selayaknya disimpan dan bahkan dikembangkan. Setelah seseorang susah payah mengumpulkan harta kekayaan, ia harus mampu menjaganya dengan baik pula. Protecting wealth is an action that prevents unsatisfactoriness from arising due to the unexpected, unintentional and/or unknowing loss of wealth, 
within the legal conditions set forth by society (Piboolsravut, 1997: 159). Dalam Sigalovada Sutta, Buddha menjelaskan kepada pemuda Sigala bahwa ada enam cara yang harus dihindari agar harta kekayaan tidak habis terhambur-hamburkan. And what six channels for dissipating wealth? The being addicted to intoxicating liquors, frequenting the streets at unseemly hours, haunting fairs the being infatuated by gamling, associating with evil companions, and the habit of idleness (Rhys Davids, 2002: 175).

4. Sikap terhadap Kekayaan

Sikap seseorang dalam memandang kekayaan sangat menentukan bagaimana ia berusaha untuk mendapatkan, menjaga, dan memanfaatkannya. For Buddhism, wealth is not evil: the important thing is how it made and use. Yet, even if wealth is made in a moral way, and used to benefit one-self and others, one should not have a greedy attitude to it (Peter Harvey, 2000: 195). Seseorang harus memperoleh kekayaan dengan cara yang bermoral dan digunakan dengan semestinya sehingga memberikan keuntungan bagi pemilik dan orang lain serta tidak menambah keserakahannya. Dalam Andha Sutta (The Blind), Buddha menjelaskan kepada para bhikkhu bagaimana seseorang harus bersikap terhadap kekayaan yang diperolehnya. Buddha mengumpamakan orang-orang di dunia ini dalam tiga kelompok, yaitu orang buta, bermata satu, dan bermata dua (Woodward, 2006: 111-112).

Memiliki kekayaan merupakan salah satu sumber kebahagiaan. Dalam Anana Sutta, Anguttara Nikaya, Buddha menjelaskan kepada Anathapindika bahwa terdapat empat macam kebahagiaan, tiga diantaranya adalah kebahagiaan yang ditimbulkan oleh harta kekayaan. Housefather, there are these four kinds of bliss to be won by householder who enjoys the pleasures of sens from time to time and when occasion offers. What four? The bliss of ownership, the bliss of wealth, the bliss of debtlessness, and the bliss of blamelessness (Woodward, 2008: 77). Kebahagiaan yang pertama adalah kebahagiaan karena memiliki harta kekayaan (atthisukha). Untuk memiliki kebahagiaan karena memiliki harta kekayaan, seseorang harus bekerja dengan benar. Bekerja dengan benar akan menghasilkan kekayaan yang dapat memberikan kebahagiaan. Kebahagiaan yang kedua adalah kebahagiaan karena dapat menikmati harta kekayaan (bhogasukha). Kekayaan yang dimiliki harus digunakan dengan cara yang benar sehingga memberikan manfaat bagi diri sendiri, orang lain, maupun lingkungan. Kebahagiaan ketiga adalah kebahagiaan karena tidak memiliki hutang (ananasukha). Meskipun demikian, Buddha menjelaskan bahwa ketiga jenis kebahagiaan tersebut masih bersifat keduniawian dan bukan tujuan akhir umat Buddha, tetapi masih ada jenis kebahagiaan lain yang lebih tinggi nilainya, yaitu kebahagiaan keempat, karena tidak tercela (blameless). Meskipun bersifat keduniawian, ketiga kebahagiaan tersebut tetap dibutuhkan oleh umat awam dalam usaha untuk mencapai kebahagiaan yang keempat.

Bagi umat Buddha, kekayaan bukan merupakan tujuan akhir tetapi sebagai alat untuk mencapai kebahagiaan yang lebih tinggi kualitasnya, yaitu nibbâna. Kebahagiaan yang lebih tinggi akan berhasil diperoleh jika didukung oleh kebahagiaan yang lebih rendah nilainya. Kekayaan seharusnya diperoleh dan digunakan dengan benar dan menghindari cara-cara tercela dalam memperoleh dan menggunakannya, seperti yang digambarkan oleh Buddha sebagai orang yang memiliki dua mata (orang bermata sehat) dalam Andha Sutta.

Segala sesuatu yang masih berkondisi bersifat tidak kekal, termasuk harta kekayaan. Karena memiliki sifat tidak kekal, maka harta kekayaan suatu ketika dapat berkurang, rusak, dan hilang. Pemahaman tentang sifat ketidakkekalan sangat membantu seseorang dalam memaknai kekayaan yang dimilikinya. Karena sifatnya itu, 
orang yang memiliki harus siap mental apabila suatu saat harta kekayaannya berkurang, rusak, atau hilang.

5. Manajemen Ekonomi Keluarga di Era Modern

Manajemen ekonomi keluarga di zaman sekarang tentu saja berbeda dengan masa kehidupan Buddha. Perbedaan tersebut berkaitan dengan jenis pekerjaan yang tersedia, kebutuhan hidup, dan sikap terhadap kekayan itu sendiri. Jarak rumah dengan tempat bekerja turut mempengaruhi pengeluaran untuk transportasi. Kantor yang jaraknya jauh dari rumah tidak dapat ditempuh dengan berjalan kaki, sehingga menuntut seseorang untuk memiliki kendaraan atau naik angkutan. Selain itu, biaya untuk pendidikan anak menjadi beban tersendiri bagi perekonomian keluarga. Dengan meningkatnya biaya untuk hidup maka dituntut pengelolaan ekonomi keluarga dengan cermat dan tepat. Di zaman yang serba materialistik dan pengaruh globalisasi yang semakin tak terbendung akan memberikan pengaruh negatif kepada setiap individu, salah satunya adalah cara pandang seseorang terhadap kekayaan yang dimiliki. Umat Buddha dituntut untuk tetap hidup sederhana. Dengan alasan ini, jenis pekerjaan dan pembagian penghasilan untuk konsumsi, investasi, dan tabungan harus disesuaikan dengan kondisi yang ada dengan tetap berpegang pada prinsip-prinsip ajaran Buddha. Manajemen ekonomi keluarga berarti pengelolaan ekonomi keluarga untuk memenuhi kebutuhan hidup sehari-hari. Mengacu pada fungsi manajemen, pengelolaan ekonomi keluarga terbagi menjadi empat tahap, yaitu: planning, organizing, actuating, dan controlling.

6. Peran Manajemen dan Ekonomi Buddhis dalam Menciptakan Kesejahteraan

Setiap keluarga memiliki permasalahan dalam memenuhi kebutuhan materi. Sandang, pangan, tempat tinggal, dan kesehatan merupakan kebutuhan dasar yang harus dipenuhi oleh setiap orang keluarga. Selain itu, kebutuhan-kebutuhan penting lain yang berhubungan dengan masyarakat dan lingkungan juga harus dipenuhi. Dalam upaya memenuhi kebutuhan tersebut, sebuah keluarga harus memperoleh penghasilan yang cukup sehingga dapat hidup secara material dengan layak. Penghasilan yang telah diperoleh harus dikelola dengan efektif dan efisien sehingga manfaatnya dapat nikmati oleh setiap anggota keluarga, bahkan orang lain dan lingkungan di sekitarnya. Dengan alasan tersebut, setiap anggota keluarga harus memiliki pengetahuan yang cukup dalam mengelola perekonomian keluarga. Pengetahuan modern tentang manajemen dapat membantu mengelola perekonomian keluarga mulai dari perencanaan, pengorganisasian, implementasi, dan pengawasannya. Nilai-nilai spiritual keagamaan berperan dalam sikap, pola pikir, dan perilaku dalam mengupayakan kesejahteraan keluarga. Gambaran hubungan antara permasalahan ekonomi keluarga, manajemen, dan nilai-nilai ajaran Buddhisme dapat ditunjukkan dalam diagram berikut ini.

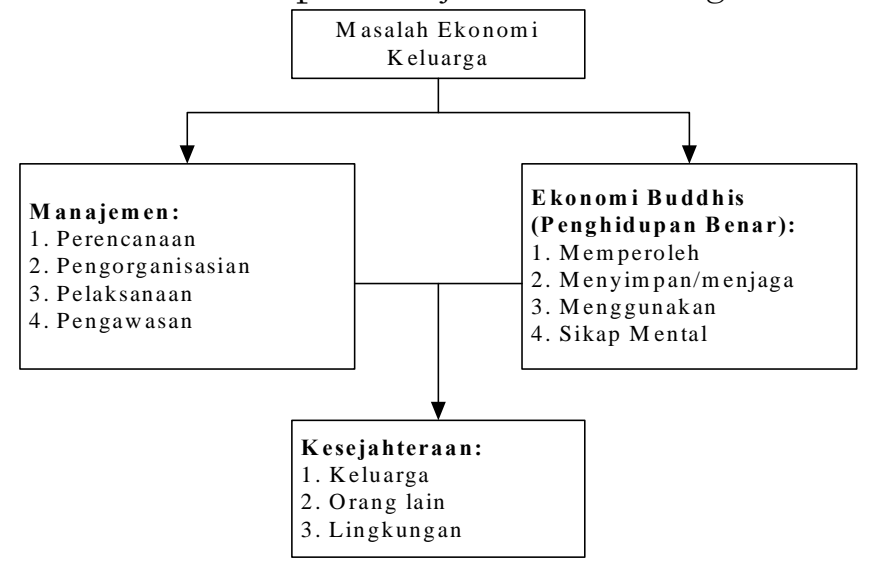




\section{Gambar l. Manajemen dan Ekonomi Buddhis Menciptakan Kesejahteraan}

Dari diagram di atas, dapat dijelaskan bahwa masalah ekonomi keluarga dapat diselesaikan melalui dua pendekatan yaitu manajemen dan nilai-nilai spiritual Buddhisme. Pengelolaan ekonomi keluarga secara modern menjadi suatu keharusan. Pengetahuan manajemen memberikan panduan bagaimana sebuah keluarga harus mengelola perekonomiannya dimulai dari perencanaan keuangan, menentukan siapa saja anggota keluarga yang harus bertanggung jawab untuk menyelesaikan berbagai tugas, pelaksanaan rencana yang telah diorganisasikan, dan pengawasannya. Melalui pengetahuan tentang manajemen yang memadai, pengelolaan perekonomian dapat menjadi efektif dan efisien, sehingga pemborosan untuk hal-hal yang tidak perlu dapat dihindarkan.

Nilai-nilai Buddhisme dapat menjadi etika yang mendasari sebuah keluarga dalam mengupayakan pemenuhan materinya. Nilai etis yang terkandung dalam Buddhisme menjadi penunjuk arah dalam berpikir, bersikap, dan berperilaku dalam memenuhi kebutuhan. Nilai etis yang terkandung dalam Buddhisme dapat dijumpai dalam Jalan Mulia Berunsur Delapan, terutama poin berpenghidupan benar. Meskipun demikian, dalam implementasinya kedelapan unsur merupakan sesuatu yang integral dan tidak dapat dipisah-pisahkan. Penjabaran lebih rinci mengenai berpenghidupan yang benar dapat digali dari berbagai ajaran Buddha yang terhimpun dalam Tripitaka. Nilai-nilai etis dalam Buddhisme memberikan petunjuk kepada umat Buddha dalam memenuhi kebutuhan materialnya, yaitu bagaimana seseorang harus mencari penghasilan, menyimpan/menjaga, menggunakan, dan sikap mental yang harus dimiliki berkaitan dengan kekayaan yang dimilikinya.

Kolaborasi antara manajemen dan nilai-nilai Buddhisme merupakan bentuk ideal dalam menyelesaikan permasalahan perekonomian, tidak hanya dalam lingkup kecil seperti individu dan keluarga, tetapi dapat menjangkau lingkup yang lebih luas, seperti kelompok masyarakat, perusahaan, dan negara. Jika ekonomi setiap keluarga diupayakan dengan cara-cara yang bermoral (sesuai dengan nilai-nilai Buddhisme) dan dikelola dengan baik (manajemen) maka kesejahteraan dan kebahagiaan keluarga dapat terwujud. Dengan terpenuhinya ekonomi keluarga dengan baik, setiap anggota keluarga dapat mengembangkan potensi yang dimiliki, baik material maupun spiritualnya. Potensi tersebut dapat disalurkan kepada orang lain dan lingkungan di sekitarnya. Dengan kecukupan secara ekonomi, sebuah keluarga dapat membantu ekonomi orang atau keluarga lain sehingga keluarga lain dapat menjadi sejahtera pula. Hasil akhir dari perpaduan manajemen dan nilai-nilai Buddhisme adalah terciptanya kesejahteraan bagi keluarga secara lahir dan batin, masyarakat, dan lingkungan. Lingkungan akan terus terjaga kelestariannya dengan diterapkannya prinsip-prinsip Buddhisme dan manajemen yang baik.

\section{Simpulan}

Penelitian ini menghasilkan pemahaman bagaimana manajemen ekonomi keluarga dalam perspektif Buddhis. Manajemen sebagai konsep modern dapat dipadukan dengan nilai-nilai ajaran Buddha dalam mengelola ekonomi keluarga. Perpaduan antara keduanya dapat menjadi panduan yang ideal. Konsep manajemen bermanfaat dalam pengelolaan perekonomian keluarga, sehingga segala sumber daya yang ada dapat dipergunakan secara efektif dan efisien. Manajemen memberikan petunjuk bagaimana sebuah keluarga harus merencanakan, mengorganisasikan, mengimplementasikan, dan mengontrol seluruh sumber daya yang dimiliki untuk menghindari pemborosan pada hal-hal yang tidak perlu. 
Nilai-nilai Buddhisme memberikan petunjuk bagaimana sebuah keluarga dapat memenuhi kebutuhan materi melalui cara-cara memperoleh penghasilan tanpa mengabaikan moralitas, kekayaan yang telah diperoleh disimpan atau dijaga, dan penggunaannya, serta sikap mental seseorang dalam memandang kekayaan yang dimiliki. Perpaduan manajemen dan Buddhisme merupakan model ideal yang dapat digunakan untuk menghadapi globalisasi ekonomi yang didominasi oleh ekonomi kapitalis yang ternyata gagal dalam menciptakan kemakmuran dan kesejahteraan kehidupan manusia, tanpa mengesampingkan dampak positifnya. Konsep ekonomi Buddhis diharapkan dapat berdampingan dan menjadi inspirasi baru bagi perkembangan ekonomi dalam lingkup mikro, seperti individu dan keluarga serta memberikan dan dalam lingkup luas seperti masyarakat, perusahaan, dan negara. Akhirnya, kesejahteraan individu, masyarakat, dapat tercapai tanpa saling merugikan dan lingkungan yang menyediakan sumber daya alam tetap terjaga kelestariannya. 


\section{Daftar Pustaka}

Bodhi, Bhikkhu. 2006. Jalan Kebahagiaan Sejati. Jakarta: Karaniya.

Buddharakkhita. 2011. The Role of a Missionary: A Buddhist Perspective. Thailand: ICDV Conference Volume, p. 29-37.

Davids, Rhys T. W. 2002. Dialogues of The Buddha. Oxford: The Pali Text Society.

Dhammasiri, Kekanadure. 2010. Buddhist Economic Thought. Kuala Lumpur: Buddhist Maha Vihara.

Endro, Herman S. 1997. Proses Transformasi Menuju Kemandiri-an Ekonomi. Jakarta: Panitia Simposium Nasional III Cendikiawan Indonesia.

Essen, Juliana. 2010. Sufficiency Economic and Santi Asoke: Buddhist Economic Ethics for Just and Sustainable World. Journal of Buddhist Ethics, Vol. 33, p. 70-99.

Field, Lloyd. 2009. Business and The Buddha: Berhasil dengan Berbuat Baik. Jakarta: Karaniya.

Fine, J. Marc. 2008. Buddha in a Business Suit. Washington: Wisdom Soft Publications.

Harvey, Peter. 2000. An Introduction to Buddhist Ethics. UK: Cam-bridge.

Inoue, Shinichi. 1997. Putting Buddhism to Work: New Approach. Tokyo: Kodansha International Ltd.

Mangkuprawira, Tb. Sjafri. 201l. Manajemen Sumber Daya Manusia Strategik. Bogor: Galia Indonesia.

Payutto, P. A. 2005. Ekonomi Buddhis: Jalan Tengah untuk Dunia Usaha (Terjemahan). Jakarta: PP Magabudhi.

Piboolsravut, Priyanut. 1997. An Outline of Buddhist Economic Theory and System. Simon Fraser University, Disertasi.

Prayukvong, Wanna. 2005. A Buddhist Economic Approach to The Development of Community Enterprises: A Case Study from Southern Thailand. Cambridge Journal of Economic, Vol. 29, p. 1171-1185.

Singh, Arvind K. 2012. Economic Management: An Interpretation from The Buddhist Perspective. Sri Lanka International Journal of Buddhist Studies (SIJBS) Vol. 2, p. 74-87.

Sutjiono, Danny. 2005. Modul Pelatihan dan Pendampingan Ekonomi Rumah Tangga. Jakarta: P2KP.

Uprety, Prem R. 1996. The Economics of Buddhism: An Alternative Model for Community Development. CNAS Journal, Vol. 23, No. 1, p. 119-124.

Virya, Jhana. 2009. Membina Keluarga Hita Sukhaya. Jakarta: Yanwreko Wahana Karya.

Widya, Dharma K. 2004. Menjadi Umat Buddha: Penuntun Pelaksanaan Agama Buddha dalam Kehidupan Sehari-hari. Jakarta: Penerbit Magabudhi, Wandani, dan Patria.

Wijebandara, Chandima. 2012. The Buddha as an Economic Adviser. Sri Lanka International Journal of Buddhist Studies (SIJBS) Vol. 2, p. 24-37.

Woodward. 2006. The Book of Gradual Saying, Vol. I. Lancaster: The Pali text Society.

Woodward. 2008. The Book of Gradual Saying, Vol. III. Oxford: The Pali text Society.

Woo, K. I. 2009. Buddhist Economics-from Schumacher to Payutto. GH Bank Housing Journal, $3(7)$, p. $12-21$.

Wowor, Cornelis. 2004. Pandangan Sosial Agama Buddha. Jakarta: Nitra Kencana Buana.

Zolnai, Laszlo. 201l. Ethical Principles and Economic Transformation - A Buddhist Approach. Springer.

Sumber Online:

http://www.accesstoinsight.org/lib/authors/dhammananda/marriage.html. 